\title{
85618 - CONSULTA DE ENFERMAGEM AO IDOSO COM DIABETES MELLITUS NA ATENÇÃO PRIMÁRIA À SAÚDE
}

\section{Pôster - Gerontologia}

\author{
Juliete Coelho Gelsleuchter / Gelsleuchter, J.C / Universidade Federal de Santa Catarina; \\ Karina Silveira de Almeida Hammerschmidt / HAMMERSCHMIDT, K. S. A / Universidade Federal de Santa \\ Catarina; \\ Juliana Balbinot Reis Girondi / GIRONDI, J. B. R / Universidade Federal de Santa Catarina; \\ Laura Cavalcanti de Farias Brehmer / BREHMER, L. C. F. / Universidade Federal de Santa Catarina; \\ Melissa Orlandi Honório Locks / HONORIO, M. O. / Universidade Federal de Santa Catarina; \\ Anderson Abreu de Carvalho / CARVALHO, A. A. / Universidade Federal de Santa Catarina
}

Introdução: A Consulta de enfermagem (CE), é oportunidade para realizar práticas do cuidado como: fortalecimento do vínculo, educação em saúde, avaliação multidimensional, identificação precoce de idosos frágeis ou em processo de fragilização, entre outras ${ }^{1}$. Objetivo: Identificar a realização da CE específica para idosos com diabetes mellitus, por enfermeiros de uma unidade básica de saúde do município de São José/SC. Metodologia: Trata-se de estudo de caso holístico, de casos múltiplos ${ }^{2}$. Participaram do estudo cinco enfermeiros de uma Unidade Básica de São José/ SC, no período de dezembro de 2016. A coleta de dados buscou evidências através de entrevista semiestruturada. Os aspectos desta pesquisa estão de acordo com a resolução 466/12 e aprovada no Comitê de ética sob parecer 1.833.375. Resultados: Quando questionados se eles teriam uma agenda exclusiva para o atendimento dos idosos diabéticos quatro participantes do estudo negam a existência deste atendimento exclusivo, negando assim a realização de $\mathrm{CE}$, pois segundo os mesmos a Secretaria da Saúde de São José passou por uma reestruturação empregando o acolhimento nas unidades de saúde. Atualmente as agendas funcionam através do acolhimento à demanda espontânea, atendendo assim todo público independente de ter uma agenda exclusiva. Apenas um enfermeiro faz consulta de enfermagem voltado aos marcadores englobado à consulta com idoso diabético. Conclusões: Nesse contexto, ressalta a importância dos enfermeiros da Estratégia da Saúde da Família e seu papel fundamental nas respostas às necessidades de saúde da população idosa na Atenção Primária. Destacando a CE como sendo atividade privativa do enfermeiro, onde é possível usar componentes do método científico para identificar situações de saúde/doença, prescrever e implementar medidas de enfermagem que contribuam para a promoção, prevenção, proteção da saúde, recuperação e reabilitação do indivíduo, família e comunidade. Reforçando que o acolhimento ajuda a criar vínculo, porém não é uma CE e muito mesmos substituí a mesma.

Palavras-chave: Idoso; Diabetes Mellitus; Enfermagem; Atenção primaria à Saúde.

Referências: 1. BRASIL. Ministério da Saúde. Secretaria de Atenção à Saúde. Envelhecimento e saúde da pessoa idosa. Ministério da Saúde, 2006. 192 p. (Cadernos de Atenção Básica, n. 19); 2. YIN, Robert. Estudo de Caso: Planejamento e Métodos. 3. ed. Porto Alegre: Bookman, 2005. 212 p. 